\title{
Evaluation of the relationship between periodontal risk and carotid artery calcifications on panoramic radiographs
}

\author{
Gulen Kamak ${ }^{1}$, Eren Yildirim² ${ }^{2}$ Emin Rencber ${ }^{3}$
}

Correspondence: Dr. Eren Yildirim

Email:dt.eren@hotmail.com

\author{
'Department of Periodontology, Faculty of Dentistry, \\ Kirikkale University, Kirikkale, Turkiye, \\ ${ }^{2}$ Department of Oral and Maxillofacial Radiology, \\ Faculty of Dentistry, Kirikkale University, \\ Kirikkale, Turkiye, \\ ${ }^{3}$ Department of Public Health, School of Medicine, \\ Ondokuz Mayıs University, Samsun, Turkiye
}

\section{ABSTRACT}

Objective: To evaluate if there is a relationship between findings of carotid artery calcification (CAC) and periodontal risk in nonsmoker subjects by using panoramic radiographs (DPR). Materials and Methods: A total of 1146 DPRs were investigated. Gender, age, severity of bone loss, tooth loss, periodontal risk, and findings of carotid calcification were recorded. The periodontal risk was evaluated and classified according to the degree of alveolar bone loss. Results: CAC was diagnosed in \%13.6 (n: 156) of DPRs. Of 1146 patients, $338(29.5 \%)$ had low, $668(60 \%)$ had moderate, and $120(10.5 \%)$ had high periodontal risk. A statistically significant relation was observed between carotid calcification and periodontal risk. Conclusion: Positive findings of carotid calcification may be related with periodontal problems. Clinicians must be careful about diagnosing CACs on DPRs during routine examinations. In the case of positive findings of CAC and periodontitis together, the patient may be consulted to a specialist for further investigation.

Key words: Calcified carotid artery, nonsmokers, panoramic radiograph, periodontitis

\section{INTRODUCTION}

Coronary artery disease (CAD) is one of the major reasons of sudden death in all over the world. There are several risk factors for CAD such as; obesity, diabetes, smoking, inactive life or genetic ${ }^{[1]}$ Atherosclerosis is the underlying cause of the CAD. Besides, this can cause ischemia, and if continues for a long time, heart attacks can occur following the myocardial cell death. ${ }^{[2]}$ Hence, early recognition of such diseases is very important.

Previous studies had revealed the relation between carotid atherosclerosis and coronary atherosclerosis. The rate of detecting carotid stenosis as calcifications in general adult population is identified as $4 \%$ while this ratio is $30-70 \%$ in a population with CAD. ${ }^{[3]}$

Calcifications are seen at bifurcation of the carotid artery and can be determined at the level of C3, C4, adjacent to cervical spine and hyoid bone as irregular radiopacity or radiopaque lines [Figure 1]. ${ }^{[4]}$

There are several diagnostic methods that have been used to establish carotid artery calcification (CACs). ${ }^{[5]}$ Sonography computed tomography (CT), magnetic resonance tomography, electronic thermography, and angiography can be considered among these methods. ${ }^{[6]}$ Compared to these methods, panoramic radiographs (DPR) present a more economic and

This is an open access article distributed under the terms of the Creative Commons Attribution-NonCommercial-ShareAlike 3.0 License, which allows others to remix, tweak, and build upon the work non-commercially, as long as the author is credited and the new creations are licensed under the identical terms.

For reprints contact: reprints@medknow.com

How to cite this article: Kamak G, Yildirim E, Rencber E. Evaluation of the relationship between periodontal risk and carotid artery calcifications on panoramic radiographs. Eur J Dent 2015;9:483-9.

DOI: $10.4103 / 1305-7456.172614$ 


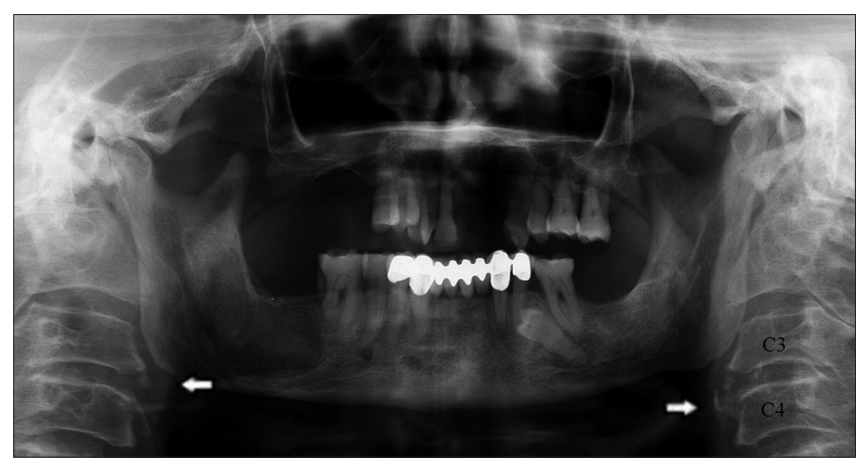

Figure 1: A panoramic radiograph of a 61-year-old man showing radio opacities in bilateral carotid vascularite areas

quick usage to examine calcifications of the carotid artery and also, DPR are carried out routinely in all patients. A number of studies reported the importance and possibilities of diagnosis of CACs on DPR. ${ }^{[7,8]}$

Chronic periodontitis (CP) is a chronic infection which is caused by Gram-negative bacteria may be induced the coronary heart disease, stroke, and atherosclerosis. ${ }^{[9]}$ Periodontopathogen microorganisms such as Porphyromonas gingivalis have been demonstrated in atherosclerotic plaques, and many studies reported an association between severe periodontal bone loss and carotid atherosclerosis. ${ }^{[10,11]}$

The aim of this study is to analyze the correlation between the presence of CACs and periodontitis on DPR retrospectively in a group of the nonsmoking population. Further, the relationship between CACs and periodontal disease risk assessment was evaluated. According to our knowledge, this is the first study investigating the relationship between periodontal risk and CACs in nonsmoker subjects.

\section{MATERIALS AND METHODS}

Approval for this study was obtained from the Ethical Committee before starting the study. A sample of 1850 radiographs of the outpatients who were being treated by the dental service at Kirikkale University was examined. Radiographs of the patients whose age were 45 years or above were selected. DPR which showed defects resulting from the imaging process of the area of interest, on which cervical vertebra regions were not visualized or which belonged to patients who has any reported systemic diseases were excluded from the study. In total, 1146 radiographs were included for the study. The presence of CACs, periodontal risk, and tooth loss were evaluated on these radiographs. A part from this, the patient-related data were produced from the selected panoramic pictures (PR). Among others, gender, age, and the date of the PR taking were recorded.

\section{Radiographic examination}

The PRs had been made using a digital panoramic system (Instrumentarium OP 200 D, 75 kVp, 10 mA, 17.6 s scan time, Tuusula, Finland). Radiographs were examined by a dentomaxillofacial radiologist (assistant professor). During the examination of these radiographs, no time limit was imposed.

\section{Evaluation of carotid artery calcifications}

Twenty percent of the remaining radiographs were selected at random and twice reevaluated by the same investigator 4 weeks after the first evaluation. Intra-examiner reproducibility was found to be $84.6 \%$ (agreement for 93/104 sides). Verticolinear oriented heterogeneous radiopacities at above or below intervertebral space C3-C4 were identified as CACs. ${ }^{[12]}$ CACs were scored as present or absent, and dentomaxillofacial radiologist approved all the positive findings. ${ }^{[13]}$ Lateral distribution of CAC was identified as unilateral or bilateral. ${ }^{[12]}$

\section{Evaluation of periodontal risk}

The periodontal risk assessment was estimated by measuring alveolar bone loss on PR. Percentage of bone loss was measured at the each tooth mesial and distal sides according to the method described by Schei et al. ${ }^{[14-16]}$ The alveolar bone crest in relation to root length was measured. Mesial and distal sides of each tooth were scored; 1, 0-24\% bone loss; 2, 25-49\% bone loss; and 3, 50-100\% bone loss. The scores were first assembled and then averaged. Besides, a single mean bone loss score was obtained for each participant as 1 , low periodontal risk; 2 , moderate periodontal risk, and 3, high periodontal risk. Edentulous patients were recorded. Mean periodontal bone loss of $50 \%$ or above corresponds with a diagnosis of severe $\mathrm{CP} .{ }^{[17]}$

\section{Statistical analysis}

SPSS for Windows, Version 18 (SPSS Inc., Chicago, Illinois, USA) was used to perform statistical analysis. Kolmogorov-Smirnov test was used to determine the normal distribution of continuous variables. For all of the variables, means and standard deviations were calculated and nonparametric tests were used. Pearson Chi-square test or Fisher's exact test were used to determine the potential differences in the distribution of categorized data. Logistic regression was used to evaluate the odds ratio for relation between the dependent variable CAC and periodontal risk among 
dentate subjects. The threshold for significance was set at $P<0.05$.

\section{RESULTS}

\section{Study population}

A total of 1850 radiographs were examined. Radiographs of patients who had been recorded as having any systemic disease (diabetes, hypertension, etc.) (329) and radiographs without clear image (375) were not included into the analysis. Among the 1146 patients, $577(50.3 \%)$ of them were males and $569(49.7 \%)$ were females. The mean age of the subjects was $53.84 \pm 9.25$ [Table 1].

\section{Analysis of periodontal risk and tooth loss}

Of the 1146 patients, 338 (29.5\%) had low periodontal risk, $688(60.0 \%)$ had moderate risk and 120 (10.5\%) had high periodontal risk. All of the patients in this study were dentate and the mean tooth loss was $9.31 \pm 7.18$ (max: 31, min: 0) [Table 1]. According to the correlation analysis, a positive correlation was observed between the age and number of missing

\begin{tabular}{|c|c|}
\hline & $(\%)$ \\
\hline Age in years (mean $\pm S D)$ & $53.84 \pm 9.25$ \\
\hline \multicolumn{2}{|l|}{ Gender (n: 1146) } \\
\hline Female & $569(49.7)$ \\
\hline Male & $577(50.3)$ \\
\hline \multicolumn{2}{|l|}{ CAC } \\
\hline None & $990(86.4)$ \\
\hline All & $156(13.6)$ \\
\hline Right sides & $40(3.5)$ \\
\hline Left sides & $52(4.5)$ \\
\hline Both sides & $64(5.6)$ \\
\hline \multicolumn{2}{|l|}{ Periodontal risk } \\
\hline Low & $338(29.5)$ \\
\hline Moderate & $688(60.0)$ \\
\hline High & $120(10.5)$ \\
\hline Tooth loss (mean $\pm S D)$ & $9.31 \pm 7.18$ \\
\hline
\end{tabular}

teeth, and there was also a significant between the periodontal risk and the number of the missing teeth of patients [Table 2].

Analysis of CACs and its distribution according to age and tooth loss:

During the radiographic analysis there was not detected any imagine of CAC in 990 cases $(86.4 \%)$ whereas it was detected in $13.6 \%(n=156)$ of 1146 cases. Among those, in $40(3.5 \%)$ cases CAC was on the right side, in $52(4.5 \%)$ cases on the left side and in $64(5.6 \%)$ cases on both sides [Table 1].

Patients with CAC were on average $56.99 \pm 8.79$-year-old whereas the patients without CAC were on average $53.35 \pm 9.23$-year-old. A highly significant correlation was detected between CAC and age of subjects $(P<0.001)$ [Tables 2 and 3 ].

CAC was detected in 82 of 569 female patients and in 74 of 577 male patients. The number of the female patients with CAC was greater than the male patients ( $14.4 \%$ and $12.8 \%$, respectively) but there was no statistically significant difference between the mean number of tooth loss $(P=0.44)$ [Table 2]. In patients with CAC, average number of tooth loss was $12 \pm 7.73$ and in patients without CAC, that number was $8.83 \pm 6.96$. The difference between the mean number of tooth loss was statistically significant $(P<0.001)$ [Table 3]. It was also seen that significant correlation between the increase of the missing teeth and prevalence of CAC was evidence [Table 2].

\section{Observation of the relationship between carotid} artery calcification and periodontal risk

In 327 of 338 patients with low periodontal risk, CAC was not observed, whereas only 11 of them had CAC on DPR. Conversely, in 62 of 120 patients with high periodontal risk, had CAC but 58 of them did not. In both groups (low, moderate, and high periodontal risk groups) there was a significant difference between the number of the patients with CAC and without CAC $(P<0.001)$ [Table 3]. It was shown that the

\begin{tabular}{lccccc}
\multicolumn{5}{l}{ Table 2: Correlation between CAC and other parameters (age, gender, periodontal risk and tooth loss) } \\
\hline \multicolumn{7}{c}{ CAC } & Age & Gender & Periodontal risk & Tooth loss \\
\hline CAC & - & - & - & - & - \\
Age & $0.135^{* * *}$ & - & - & - & - \\
Gender & $-0.023 \mathrm{NS}$ & $-0.068^{*}$ & - & - & - \\
Periodontal risk & $0.341^{* * *}$ & $-0.155^{* * *}$ & $0.086^{* *}$ & - & - \\
Tooth loss & $0.171^{* * *}$ & $0.513^{* * *}$ & $-0.022 \mathrm{NS}$ & $0.094^{* *}$ & -05 \\
\hline${ }^{* * *} P<0.001,{ }^{* *} P<0.01,{ }^{*} P<0.05, \mathrm{NS}:$ Not significant) & & &
\end{tabular}


Kamak, et al.: Periodontal risk and calcified carotid artery

\begin{tabular}{|c|c|c|c|c|}
\hline & \multirow{2}{*}{$\begin{array}{c}\text { Mean value } \\
(\%)\end{array}$} & \multicolumn{2}{|c|}{ CAC } & \multirow[t]{2}{*}{ Significance } \\
\hline & & Yes (n: 156) (\%) & No $(n: 990)(\%)$ & \\
\hline Age in years (mean $\pm S D)$ & $53.84 \pm 9.25$ & $56.99 \pm 8.79$ & $53.35 \pm 9.23$ & $P<0.001^{* * *}$ \\
\hline Gender & & & & $P: 0.44 \mathrm{NS}$ \\
\hline Female & $569(49.7)$ & $82(14.4)$ & $487(85.6)$ & \\
\hline Male & $577(50.3)$ & $74(12.8)$ & $503(87.2)$ & \\
\hline Periodontal risk & & & & $P<0.001^{* * *}$ \\
\hline Low & $338(29.5)$ & $11(3.3)$ & $327(96.7)$ & \\
\hline Moderate & $688(60.0)$ & $83(12.1)$ & $605(87.9)$ & \\
\hline High & $120(10.5)$ & $62(51.7)$ & $58(48.3)$ & \\
\hline Tooth loss (mean \pm sd) & $9.31 \pm 7.18$ & $12.40 \pm 7.73$ & $8.83 \pm 6.96$ & $P<0.001^{* * *}$ \\
\hline
\end{tabular}

greater the periodontal risk, the greater the prevalence of the CAC [Tables 2 and 3]. Hence, the relationship between CAC and periodontal risk was statistically significant [Table 2].

\section{DISCUSSION}

Periodontal disease is one of the most prevalent chronic infections in humans and can be very important as a result of its possible contribution to vascular disease. ${ }^{[17-19]}$ There are several studies with different results examining the relationship between cardiovascular diseases (CVDs) that has vital importance and periodontitis. In these studies several systemic markers, clinical or radiographic findings have been used to determine the relationship between two diseases. According to many studies, CAC is one of the subclinical finding of cardiovascular problems. In a previous study, it was reported that the subjects having CAC detected on DPR had a higher risk of stroke, sudden death, and myocardial infarction than the others. ${ }^{[20]}$ It has been observed that when carotid artery occlusion is more than $60 \%$ surgical removing of the atheroma from the blocked artery decreases the risk of stroke in half. ${ }^{[21]}$

There is a lack of studies investigating the relationship between periodontitis and $\mathrm{CAC}$, as a radiographic finding of CVDs. Moreover, these studies have not been focused on smoking, which is considered as an important risk factor for CVDs and periodontitis. To best our knowledge, this study is the first one investigating the relationship between a calcified carotid artery and periodontitis in a nonsmoking population.

CAC can be observed by different diagnostic methods. Sonography which is one of the noninvasive techniques has been stated as "the gold standard" in the examination of atherosclerotic changes such as the carotid artery. ${ }^{[5]}$ However, identifying the carotid artery in DPR as true calcification can be quite conceivable. In some studies, positive findings of the carotid artery on Doppler sonography have been confirmed using DPR. ${ }^{[22,23]}$ In another study, it was reported that the confirmation of radiographic image of CACs by ultrasound and CT was $34.7 \%$ and $62.3 \%$, respectively. ${ }^{[24]}$ The sensitivity and specificity of PR were $22.2 \%$ and $90 \%$, respectively. ${ }^{[25]}$ Moreover, also, taking DPR is less time consuming and routinely taken from all of the patients older than 18-year-old applying with a dental complaint. In light of these information, we used DPR to examine the CAC of the patients. ${ }^{[26,27]}$

Ohba et al. reported that calcified carotid artery had been detected on $5 \%$ of 659 DPR $(n=33)$ of the patients who were 80 -year-old. ${ }^{[28]}$ In another study performed on DPR of subjects with a mean age of $68(n=1879)$, CAC was observed in $3.8 \%$ of all radiographs $(n=71) \cdot{ }^{[22]}$ In our study, a number of 1146 radiographs were investigated, and CAC was detected on $156(13.6 \%)$ of them. The bigger ratio of carotid artery findings in our study which is similar to the results of Tiller et al., can be explained by the differences in age, lifestyles or other risk factors of the patients. ${ }^{[29]}$ In another study that was carried out in the Turkish population, like in our study, CAC was detected on 70 of total 105 DPR. ${ }^{[30]}$ This bigger ratio from the others can be attributed to differences in ethnicity.

The aim of this study was to evaluate the relationship between CAC and risk of periodontitis in nonsmoking patients. Smoking status of patients is important when the study is about periodontitis or CVD. ${ }^{[31-33]}$ 
It was reported that if the subjects are nonsmokers, the significance of a relationship between CVD and periodontitis is not apparent. ${ }^{[3,35]}$ Nevertheless, our study subjects consisted of nonsmokers, and the relationship between CAC-positive status and having periodontitis is statistically significant. This unexpected result may be caused by the different risk factors of CVD such as genetics, obesity, or idiopathic hypertension.

$\mathrm{CP}$ is an infectious disease which leads to the destruction of the periodontium. The presence and degree of alveolar bone destruction detected in DPR give us information about the presence and degree of periodontitis. Schei ruler method in radiographic studies examining periodontitis has been usually preferred to use. ${ }^{[14,15,36]}$ Furthermore, a strong correlation was reported between severity of periodontitis and alveolar bone destruction which was observed by using this method. And in this study we investigated the degree of bone destruction by this method.

We investigated the relationship between a calcified carotid artery and periodontal risk through measuring radiographic bone loss and number of tooth loss. According to the present study, there is a statistically significant relationship between a calcified carotid artery and also a number of tooth loss. Similarly to the present one, a recent study reported a relationship between increased risk of stroke and number of missing teeth. ${ }^{[37]}$ Others investigating oral health and CVDs presented different results. ${ }^{[38-41]}$ These studies have evaluated the relationship between risk of different CVDs and tooth loss whereas we have investigated calcified carotid artery as one of the outcomes of CVD. Calcified carotid artery which was reported as in relation with periodontal risk in the present study can be the potential pathway of affecting vascular diseases by oral health.

According to the results of our study, positive findings of CAC on DPR showed a significant relationship with age. It's well-known that increase in age is a risk factor for stroke and heart attack. Furthermore, in patients with age 50 and above, increase in arteriosclerosis of carotid artery is associated with coronary heart disease and this finding has an important role in identifying coronary heart disease. ${ }^{[42]}$

In addition, significant correlation between the risk of periodontitis and tooth loss with the presence of CACs is considerable. The result is in accordance with other studies reported a noticeable relationship between increased risk of periodontitis and positive findings of CACs. ${ }^{[43,44]}$ Engebretson et al. who confirmed findings of CACs on panoramics with Doppler sonography, found a significant relationship between loss of alveolar bone and CACs. ${ }^{[4]}$ In another study, a significant association between intermedia thickness of carotid artery and risk of periodontitis had been reported. ${ }^{[11]}$ In several studies, the significant relationship had been confirmed between CVD and periodontitis. ${ }^{[45-48]}$ Madianos et al. reported a strong relationship between periodontal disease and coronary heart disease. ${ }^{[49]}$ In another study, Christou et al. concluded that periodontal disease was associated with both high blood pressure and presence of CACs. ${ }^{[4]}$

\section{Limitations of the study}

As a result of retrospective characteristic of this study, (1) CAC findings on DPR were not confirmed with another diagnostic method such as Doppler sonography. (2) There is no information about the intermedia thickness of carotid artery. (3) There is a lack of information about risk factors such as diet habits, genetic factors, and systemic conditions. (4) Evaluation of the periodontal status of the patients depends on only radiographic examination with lack of clinical assessment. Hence, the present study has some limitations similarly to many of cross-sectional data and the relationship detected in this study should not be interpreted as causal.

\section{CONCLUSION}

The results of this study demonstrated that there is a relationship between patients with positive readings of CAC on PR and periodontitis. In addition, this relationship confirms the relationship between periodontitis and CVDs. Periodontitis is one of the most prevalent periodontal diseases in general population and as a result of such relationship with CVD periodontitis it would become a more critical disease for public health. ${ }^{[50,51]}$ Clinicians should examine the presence of carotid calcifications on PRs of the patients who has periodontitis and if they detect any sign of carotid calcifications, the patients should be referred to a cardiologist for a further examination.

\section{Acknowledgment}

This study was submitted as an oral presentation in the $19^{\text {th }}$ Congress of the Balkan Stomatological Society - BaSS, 24-27 April 2014, Belgrade, Serbia.

\section{Financial support and sponsorship}

Nil. 


\section{Conflicts of interest}

There are no conflicts of interest.

\section{REFERENCES}

1. Pornprasertsuk-Damrongsri S, Thanakun S. Carotid artery calcification detected on panoramic radiographs in a group of Thai population. Oral Surg Oral Med Oral Pathol Oral Radiol Endod 2006;101:110-5.

2. Suyambukesan S, Perumal GL. Correlation between the detection of carotid artery calcifications on panaromic radiographs and the presence of the potential risk factors. J Dent Clin 2012;4:10-3.

3. Mannami T, Konishi M, Baba S, Nishi N, Terao A. Prevalence of asymptomatic carotid atherosclerotic lesions detected by high-resolution ultrasonography and its relation to cardiovascular risk factors in the general population of a Japanese city: The Suita study. Stroke 1997;28:518-25.

4. Christou P, Leemann B, Schimmel M, Kiliaridis S, Müller F. Carotid artery calcification in ischemic stroke patients detected in standard dental panoramic radiographs - A preliminary study. Adv Med Sci 2010;55:26-31.

5. Wyman RA, Fraizer MC, Keevil JG, Busse KL, Aeschlimann SE, Korcarz CE, et al. Ultrasound-detected carotid plaque as a screening tool for advanced subclinical atherosclerosis. Am Heart J 2005;150:1081-5.

6. Handa N, Matsumoto M, Maeda H, Hougaku H, Kamada T. Ischemic stroke events and carotid atherosclerosis. Results of the Osaka Follow-up Study for Ultrasonographic Assessment of Carotid Atherosclerosis (the OSACA Study). Stroke 1995;26:1781-6.

7. Friedlander AH, Gratt BM. Panoramic dental radiography as an aid in detecting patients at risk for stroke. J Oral Maxillofac Surg 1994;52:1257-62.

8. Friedlander AH, Maeder LA. The prevalence of calcified carotid artery atheromas on the panoramic radiographs of patients with type 2 diabetes mellitus. Oral Surg Oral Med Oral Pathol Oral Radiol Endod 2000;89:420-4.

9. Haraszthy VI, Zambon JJ, Trevisan M, Zeid M, Genco RJ. Identification of periodontal pathogens in atheromatous plaques. J Periodontol 2000;71:1554-60.

10. Ravon NA, Hollender LG, McDonald V, Persson GR. Signs of carotid calcification from dental panoramic radiographs are in agreement with Doppler sonography results. J Clin Periodontol 2003;30:1084-90.

11. Beck JD, Elter JR, Heiss G, Couper D, Mauriello SM, Offenbacher S. Relationship of periodontal disease to carotid artery intima-media wall thickness: The atherosclerosis risk in communities (ARIC) study. Arterioscler Thromb Vasc Biol 2001;21:1816-22.

12. Almog DM, Horev T, Illig KA, Green RM, Carter LC. Correlating carotid artery stenosis detected by panoramic radiography with clinically relevant carotid artery stenosis determined by duplex ultrasound. Oral Surg Oral Med Oral Pathol Oral Radiol Endod 2002;94:768-73.

13. Madden RP, Hodges JS, Salmen CW, Rindal DB, Tunio J, Michalowicz BS, et al. Utility of panoramic radiographs in detecting cervical calcified carotid atheroma. Oral Surg Oral Med Oral Pathol Oral Radiol Endod 2007;103:543-8.

14. Bassiouny MA, Grant AA. The accuracy of the Schei ruler: A laboratory investigation. J Periodontol 1975:46:748-52.

15. Schei O. Alveolar bone loss as related to oral hygiene and age. J Periodontol 1959;30:7-16.

16. Björn $\mathrm{H}$, Holmberg $\mathrm{K}$. Radiographic determination of periodontal bone destruction in epidemiological research. Odontol Revy 1966;17:232-50.

17. Papapanou PN. Epidemiology of periodontal diseases: An update. J Int Acad Periodontol 1999;1:110-6.

18. Renvert S, Ohlsson O, Persson S, Lang NP, Persson GR. Analysis of periodontal risk profiles in adults with or without a history of myocardial infarction. J Clin Periodontol 2004;31:19-24.

19. Dietrich T, Sharma P, Walter C, Weston P, Beck J. The epidemiological evidence behind the association between periodontitis and incident atherosclerotic cardiovascular disease. J Clin Periodontol 2013;40 Suppl 14:S70-84.

20. Cohen SN, Friedlander AH, Jolly DA, Date L. Carotid calcification on panoramic radiographs: An important marker for vascular risk. Oral Surg Oral Med Oral Pathol Oral Radiol Endod 2002;94:510-4.
21. Towne JB, Hobson RW $2^{\text {nd }} .4$ Current status of operative treatment for asymptomatic carotid stenosis. Can J Surg 1994;37:128-34.

22. Khambete N, Kumar R, Risbud M, Joshi A. Reliability of digital panoramic radiographs in detecting calcified carotid artery atheromatous plaques: A clinical study. Indian J Dent Res 2014;25:36-40.

23. Ezoddini-Ardakani F, Mirzaei M, Nayer S, Besharati S, Moeini M. Evaluation of positive predictive value for digital panoramic radiography in comparison to ultrasound in the diagnosis of calcified carotid atheroma. Health 2014;6:1933-40.

24. Bayram B, Uckan S, Acikgoz A, Müderrisoglu H, Aydinalp A. Digital panoramic radiography: A reliable method to diagnose carotid artery atheromas? Dentomaxillofac Radiol 2006;35:266-70.

25. Yoon SJ, Yoon W, Kim OS, Lee JS, Kang BC. Diagnostic accuracy of panoramic radiography in the detection of calcified carotid artery. Dentomaxillofac Radiol 2008;37:104-8.

26. Tamura T, Inui M, Nakase M, Nakamura S, Okumura K, Tagawa T. Clinicostatistical study of carotid calcification on panoramic radiographs. Oral Dis 2005;11:314-7.

27. Sung EC, Friedlander AH, Kobashigawa JA. The prevalence of calcified carotid atheromas on the panoramic radiographs of patients with dilated cardiomyopathy. Oral Surg Oral Med Oral Pathol Oral Radiol Endod 2004;97:404-7.

28. Ohba T, Takata Y, Ansai T, Morimoto Y, Tanaka T, Kito S, et al. Evaluation of calcified carotid artery atheromas detected by panoramic radiograph among 80-year-olds. Oral Surg Oral Med Oral Pathol Oral Radiol Endod 2003;96:647-50.

29. Tiller R, Bengel W, Rinke S, Ziebolz D. Association between carotid area calcifications and periodontal risk: A cross sectional study of panoramic radiographic findings. BMC Cardiovasc Disord 2011;11:67.

30. Ertas ET, Sisman Y. Detection of incidental carotid artery calcifications during dental examinations: Panoramic radiography as an important aid in dentistry. Oral Surg Oral Med Oral Pathol Oral Radiol Endod 2011;112:e11-7.

31. Cullinan MP, Westerman B, Hamlet SM, Palmer JE, Faddy MJ, Lang NP, et al. A longitudinal study of interleukin-1 gene polymorphisms and periodontal disease in a general adult population. J Clin Periodontol 2001;28:1137-44.

32. Bergström J. Tobacco smoking and chronic destructive periodontal disease. Odontology 2004;92:1-8.

33. Wood D, Joint European Societies Task Force. Established and emerging cardiovascular risk factors. Am Heart J 2001;141 2 Suppl: S49-57.

34. Persson RE, Hollender LG, Powell VL, MacEntee M, Wyatt CC, Kiyak HA, et al. Assessment of periodontal conditions and systemic disease in older subjects. II. Focus on cardiovascular diseases. J Clin Periodontol 2002;29:803-10.

35. Vedin O, Hagstrom E, Gallup A, Neely ML, Stewart R, Koeing W, et al. Periodontal disease in patients with chronic coronary heart disease: Prevalence and association with cardiovascular risk factors. Eur J Prev Cardiol 2014;10:51-9.

36. Albandar JM, Rise J, Gjermo P, Johansen JR. Radiographic quantification of alveolar bone level changes. A 2-year longitudinal study in man. J Clin Periodontol 1986;13:195-200.

37. Joshipura KJ, Hung HC, Rimm EB, Willett WC, Ascherio A Periodontal disease, tooth loss, and incidence of ischemic stroke. Stroke 2003;34:47-52.

38. Loesche WJ, Schork A, Terpenning MS, Chen YM, Kerr C, Dominguez BL. The relationship between dental disease and cerebral vascular accident in elderly United States veterans. Ann Periodontol 1998;3:161-74.

39. DeStefano F, Anda RF, Kahn HS, Williamson DF, Russell CM. Dental disease and risk of coronary heart disease and mortality. BMJ 1993;306:688-91.

40. Wiener RC, Sambamoorthi U. Cross-sectional association between the number of missing teeth and cardiovascular disease among adults aged 50 or older: BRFSS 2010. Int J Vasc Med 2014;2014:421567.

41. Rosado A, Marcos H, Gómez P. Scientific evidence for the relationship between periodontitis and cardiovascular disease. World J Cardiovasc Dis 2013;3:62-8.

42. Craven TE, Ryu JE, Espeland MA, Kahl FR, McKinney WM, Toole JF, et al. Evaluation of the associations between carotid artery atherosclerosis and coronary artery stenosis. A case-control study. Circulation 1990;82:1230-42.

43. Beckstrom BW, Horsley SH, Scheetz JP, Khan Z, Silveira AM, Clark SJ, et al. Correlation between carotid area calcifications and 
periodontitis: A retrospective study of digital panoramic radiographic findings in pretreatment cancer patients. Oral Surg Oral Med Oral Pathol Oral Radiol Endod 2007;103:359-66.

44. Engebretson SP, Lamster IB, Elkind MS, Rundek T, Serman NJ, Demmer RT, et al. Radiographic measures of chronic periodontitis and carotid artery plaque. Stroke 2005;36:561-6.

45. Dietrich T, Jimenez M, Krall Kaye EA, Vokonas PS, Garcia RI. Age-dependent associations between chronic periodontitis/edentulism and risk of coronary heart disease. Circulation 2008;117:1668-74.

46. Katz J, Chaushu G, Sharabi Y. On the association between hypercholesterolemia, cardiovascular disease and severe periodontal disease. J Clin Periodontol 2001;28:865-8.

47. Ramírez JH, Parra B, Gutierrez S, Arce RM, Jaramillo A, Ariza Y, et al. Biomarkers of cardiovascular disease are increased in untreated chronic periodontitis: A case control study. Aust Dent J 2014;59:29-36.

48. Kodovazenitis G, Pitsavos C, Papadimitriou L, Vrotsos IA, Stefanadis C, Madianos PN. Association between periodontitis and acute myocardial infarction: A case-control study of a nondiabetic population. J Periodontal Res 2014;49:246-52.
49. Madianos PN, Bobetsis GA, Kinane DF. Is periodontitis associated with an increased risk of coronary heart disease and preterm and/or low birth weight births? J Clin Periodontol 2002;29 Suppl 3:22-36.

50. Desvarieux M. Periodontal disease, race, and vascular disease. Compend Contin Educ Dent 2001;22:34-41.

51. Papapanou PN. Periodontal diseases: Epidemiology. Ann Periodontol 1996;1:1-36.

\begin{tabular}{|l|l|}
\hline \multicolumn{2}{|c|}{ Access this article online } \\
\hline Quick Response Code: \\
\hline
\end{tabular}

